\title{
Pemahaman Perawat Mengenai Medication Safety Practice (MSP) di Bangsal Perawatan Kanker Anak RSUP Dr. Sardjito
}

Sri Mulatsih, Iwan Dwiprahasto, Sutaryo

Bagian Ilmu Kesehatan Anak Fakultas Kedokteran Universitas Gadjah Mada/RSUP Dr. Sardjito, Yogyakarta

Latar belakang. Prosedur aman pemberian obat (medication safety practice/MSP), khususnya kemoterapi, dari sudut pandang manajemen sangat penting dikaji dengan harap luaran yang lebih baik pada pasien kanker anak.

Tujuan. Mengetahui pemahaman perawat terhadap MSP pada pemberian kemoterapi untuk pasien kanker anak dengan LLA di RSUP Dr. Sardjito

Metode. Dilakukan penelitian dengan rancang bangun pra dan pasca kuasi eksperimental. Subjek adalah perawat yang melakukan pelayanan pasien kanker anak. Intervensi berupa sosialisasi kebijakan, buku panduan, dan pelatihan MSP. Diukur luaran tingkat pemahaman perawat sebelum dan sesudah intervensi dengan menggunakan kuesioner.

Hasil. Tidak ada perbedaan karakteristik subjek (24 pra dan 23 pasca intervensi). Dibandingkan pra intervensi, pada pasca intervensi didapatkan peningkatan jumlah perawat yang mendapat materi MSP (82\% vs 46\%, p=0,027), pemahaman MSP (87\% vs 42\%), dan implementasi MSP (100\% vs 71\%, p=0,019). Pasca intervensi juga didapatkan peningkatan tindakan identifikasi pasien, prinsip 6 benar cara pemberian obat, perencanaan pemberian dan peresepan kemoterapi sesuai protokol, penggunaan formulir pemesanan dan peresepan obat kempoterapi yang standar, dan labelisasi obat kemoterapi yang standar.

Kesimpulan. Pemahaman perawat mengenai MSP meningkat setelah dilakukan pelatihan dan sosialisasi buku pedoman. Implementasi MSP mengalami peningkatan di beberapa jenis tindakan, namun masih diperlukan peningkatan pemahaman khususnya pengertian MSP dan jenis tindakan MSP. Diperlukan metoda pelatihan yang lebih spesifik untuk meningkatkan pemahaman MSP khususnya perawat. Sari Pediatri 2016; 17(6):463-8.

Kata kunci: pemahaman, perawat, medication safety practice

\section{Nurse's Understanding about Medication Safety Practice (MSP) at Childhood Cancer Care Ward at Dr. Sardjito Hospital, Yogyakarta, Indonesia}

Sri Mulatsih, Iwan Dwiprahasto, Sutaryo

Background. Safety procedures in the administration of drugs (medication safety practices/MSP) particularly for chemotherapy when viewed from the management standpoint are very important to be studied, for better outcomes for pediatric cancer patients. Methods. The study was conducted with the design pre and post quasi-experimental. Subjects were nurses who are assigned to care for childhood cancer patients. Intervention are socialization of policies, handbooks and training on MSP. Outcomes: the level of understanding of nurses before and after intervention, using questionnaires.

Results. No differences in subjects characteristics (24 pre-intervention and post-intervention 23) before and after the intervention. Compared to pre-intervention, post-intervention found an increased of the number of nurses who received MSP material (82\% vs $46 \%, \mathrm{p}=0.027)$, MSP understanding ( $87 \%$ vs $42 \%)$, and the implementation of MSP ( $100 \%$ vs $71 \%$, $\mathrm{p}=0.019)$. In addition the post-intervention also found increased in actions for patient identification, six principles of correct way of drug administration, planning, administration and prescription of appropriate chemotherapy protocol, use the booking form and the standard prescription, and standard drug labeling of chemotherapy.

Conclusion. Nurses understanding about MSP increased after training and socialization of guidebook. Implementation of MSP increased in some kind of action, but still needs to improve understanding of the particular sense of MSP and the type action for MSP. Further specific training methods are required to improve the understanding of the MSP especially for the nurses.

Sari Pediatri 2016; 17(6):463-8.

Keywords: comprehension-nurse-medication safety practice

Alamat korespondensi: Dr. dr. Sri Mulatsih, MPH, SpAK. KSM IKA, RSUP Dr. Sardjito. Jl. Kesehatan No.1, Sekip Utara, Yogyakarta.

E-mail: smulat@gmail.com 
Sri Mulatsih dkk: Pemahaman perawat mengenai medication safety practice (MSP) di bangsal perawatan kanker anak

$\mathrm{P}$ enelitian Supriyadi dkk ${ }^{1}$ di RSUP Dr Sardjito menunjukkan perkiraan average annual incidence rate (AAIR) anak dengan leukemia akut adalah 46,2/1000 000 anak per tahun. Hal menarik yang diungkapkan penelitian tersebut adalah adanya peningkatan annual incidence rate (AIR) secara bermakna dari 35/1 000000 pada tahun 1999 menjadi 70/1 000000 pada tahun 2009 .

Pelayanan onkologi anak merupakan area risiko terjadinya harm pada pasien karena kejadian tidak diinginkan (KTD) akibat kompetensi perawat, manajemen kebijakan dan infrastruktur. Alat prosedur standar yang komprehensif untuk menjaga keamanan atau mencegah medical error (ME) pada pemberian kemoterapi pada pasien kanker umumnya dan pada anak dengan leukemia limfoblatik akut (LLA) anak masih belum ada di Indonesia. Akibatnya adalah kesalahan yang terjadi tidak dapat dipecahkan secara komprehensif.

Medication safety practice (MSP) merupakan praktik prosedur yang aman dalam pengobatan. Dengan MSP, sistem pengobatan berjalan sesuai dengan prosedur, tujuan yang jelas, serta mempelajari kejadian ME yang terjadi dalam lingkungan pelayanan pengobatan. ${ }^{2}$ Khusus kemoterapi pada pasien kanker anak (LLA sebagai jenis kanker terbanyak) apabila dilihat dari sudut pandang manajemen, MSP sangat penting untuk dikaji dengan harapan luaran yang lebih baik. Beberapa hal terkait prosedur yang aman dalam pemberian kemoterapi adalah adanya prosedur standar dari beberapa tahap yang harus dilakukan, yaitu review informasi klinis dan seleksi regimen kemoterapi, rencana pengobatan dan informed consent, persiapan obat, keteraturan pengobatan, pemberian dan pemantauan kemoterapi, serta monitoring respons dan efek samping obat. Adanya prosedur standar dalam pemberian kemoterapi yang aman diharapkan dapat menurunkan angka ME pada pasien kanker anak terutama LLA.

Berdasarkan latar belakang tersebut, perlu dilakukan penelitian untuk mengetahui pemahaman perawat terhadap MSP pada pemberian kemoterapi untuk pasien kanker anak dengan LLA di RSUP Dr. Sardjito.

\section{Metode}

Penelitian dilakukan secara kuasi eksperimental dengan mengukur pemahaman perawat megenai MSP dengan ancang bangun pra- dan pasca intervensi.
Luaran yang diukur adalah pemahaman perawat mengenai MSP. Intervensi yang dilakukan berupa penyusunan kebijakan, penyusunan buku panduan, pelatihan tentang MSP. Subjek yang diteliti adalah pasien yang dirawat, baik baru ataupun lama, dengan diagnosis LLA. Periode pra tes dan pasca tes masingmasing selama 1 bulan. Tempat penelitian di Bagian Hematologi-Onkologi Anak RSUP DR Sardjito sebagai pusat rujukan kanker di Daerah Istimewa Yogyakarta dan sekitarnya. Periode waktu penelitian adalah mulai bulan September 2012 - Mei 2013. Kuesioner mengenai pemahaman standar prosedur kemoterapi yang aman didistribusikan kepada tenaga medis yang terlibat dalam kemoterapi di bangsal kanker anak RSUP Dr Sardjito Yogyakarta. Kuesioner diberikan dua kali, yakni pada September 2013 yang selanjutnya disebut sebagai tahap pra tes, dan pada Juni 2014 yang selanjutnya disebut sebagai tahap pasca tes.

Pengujian reliabilitas alat ukur dilakukan uji coba kuesioner di bangsal rawat inap anak RSUP Dr Sardjito. Uji coba instrumen ini menggunakan 30 orang responden. Pada hasil uji validitas dan realibilitas di dapatkan nilai alpha cronbach 0.711 dan valid karena $r$ hitung tidak ada yang kurang dari $r$ table dan tidak ada peningkatan nilai alpha cronbach bila item dihapus yang berarti bawa kuesioner valid dan realibel.

\section{Hasil}

Dari Tabel 1 didapatkan tidak ada perbedaan yang bermakna mengenai karakteristik responden baik sebelum dan setelah intervensi. Didapatkan bahwa sebagian besar responden adalah wanita baik sebelum maupun sesudah intervensi ( $96 \%$ vs 100\%), dan hanya sebagian kecil adalah pria ( $4 \%$ vs $0 \%$ ). Pendidikan terakhir responden sebagian besar (63\% vs $78 \%$ ) lulusan D3 keperawatan. Seluruh responden (100\%) yang bekerja di perawatan kanker anak sudah mempunyai ijin praktek. Sebagian besar (50\% vs 57\%) responden bekerja di bangsal Estella 2 dan Estella 1 (29\% vs 26\%), dengan masing masing ada 24 responden saat pra dan 23 responden saat pasca intervensi.

Tabel 2 menunjukkan pemahaman responden mengenai MSP. Tampak dari Tabel 2 bahwa terdapat peningkatan yang signifikan dalam hal pernah mendengar istilah MSP $(\mathrm{p}=0,041)$ dari materi pelatihan dan buku pedoman mengenai MSP $(p=0,027)$ sesudah intervensi. 
Sri Mulatsih dkk: Pemahaman perawat mengenai medication safety practice (MSP) di bangsal perawatan kanker anak

Tabel 1. Karakteristik data dasar

\begin{tabular}{lccc}
\hline Karakteristik & Pra & Pasca & \multirow{2}{*}{$\mathrm{p}$} \\
\cline { 2 - 3 } & $\mathrm{n}=24$ & $\mathrm{n}=23$ & \\
\hline Jenis kelamin & 23 & 23 & \\
$\quad$ Perempuan & 1 & 0 & \\
Laki-laki & 2 & 222 & 0,217 \\
Pendidikan terakhir & 15 & 18 & \\
SLTA & 2 & 2 & \\
D3 & 4 & 1 & \\
S1 & 1 & 0 & \multirow{2}{*}{0,223} \\
Dokter & & & \\
Apoteker & 19 & 22 & \\
Pekerjaan & 4 & 1 & \\
Perawat & 1 & 0 & \\
Dokter residen & 24 & 23 & \\
Ahli Farmasi & & & 0,297 \\
Surat ijin bekerja & 3 & 1 & \\
Lokasi kerja & 7 & 6 & \\
Bagian Hematologi-onkologi anak & 12 & 13 & \\
Perawat di Bangsal Estella 1 & 1 & 3 & \\
Perawat di Bangsal Estella 2 & 1 & 0 & \\
Perawat di Poliklinik Hematologi-onkologi Anak & 8,3 & 10,7 & 0,411 \\
Bagian Farmasi & &
\end{tabular}

${ }^{*} \mathrm{p}<0,05$ secara statistik bermakna apabila ada perbedaan karakteristik responden

Tabel 2. Pengetahuan responden mengenai MSP

\begin{tabular}{|c|c|c|c|c|}
\hline \multirow[t]{2}{*}{ No } & \multirow[t]{2}{*}{ Pertanyaan penelitian } & Pra & Pasca & \multirow[t]{2}{*}{$\mathrm{p}$ value } \\
\hline & & $\mathrm{n}=24$ & $\mathrm{n}=23$ & \\
\hline \multirow[t]{3}{*}{1} & $\begin{array}{l}\text { Apakah responden pernah mendengar } \\
\text { istilah MSP? }\end{array}$ & & & \\
\hline & Pernah & 20 & 23 & $0,041^{*}$ \\
\hline & Tidak pernah & 4 & 0 & \\
\hline \multirow[t]{3}{*}{2} & $\begin{array}{l}\text { Apakah responden mengetahui apakah } \\
\text { MSP itu? }\end{array}$ & & & \\
\hline & Ya & 18 & 22 & 0,132 \\
\hline & Tidak tahu & 6 & 1 & \\
\hline \multirow[t]{4}{*}{3} & $\begin{array}{l}\text { Apakah responden pernah mendapat } \\
\text { materi mengenai MSP? }\end{array}$ & & & \\
\hline & Pernah & 11 & 19 & $0,027^{*}$ \\
\hline & Tidak pernah & 9 & 2 & \\
\hline & Lupa & 4 & 2 & \\
\hline 4 & $\begin{array}{l}\text { Menurut responden apakah MSP perlu } \\
\text { diketahui? }\end{array}$ & & & - \\
\hline
\end{tabular}

${ }^{*} \mathrm{p}<0,05$, secara statistik bermakna ada kenaikan persentasi responden dalam hal pernah mendengar istilah dan pelatihan mengenai MSP 
Sri Mulatsih dkk: Pemahaman perawat mengenai medication safety practice (MSP) di bangsal perawatan kanker anak

Tabel 3. Pengetahuan responden mengenai definisi MSP

\begin{tabular}{llcc}
\hline No & Apakah MSP itu ? & & \\
\cline { 2 - 3 } & Jawaban responden & $\begin{array}{c}\text { Pra } \\
\mathrm{n}=24\end{array}$ & $\begin{array}{c}\text { Pasca } \\
\mathrm{n}=23\end{array}$ \\
\hline 1 & $\begin{array}{l}\text { Cara pemberian obat yang sesuai dengan prinsip 6 benar yang bertujuan untuk keselamatan } \\
\text { pasien. }\end{array}$ & 5 & 0 \\
2 & $\begin{array}{l}\text { Pencegahan kesalahan dalam memberikan terapi untuk pasien baik dari identifikasi pasien, } \\
\text { tindakan aseptik, higien tangan, tepat pasien, tepat cara pemberian ke pasien. }\end{array}$ & 2 & 0 \\
3 & $\begin{array}{l}\text { Proses standar yang tercatat pelaksana, perencanaan, standar pemberian obat (dan standar } \\
\text { lain yang terikat) guna mencegah terjadinya medication error/mencapai luaran pasien yang } \\
\text { diharapkan. } \\
\text { Kebijakan dan prosedur aman pengobatan kemoterapi mulai dari review informasi } \\
\text { klinis, seleksi regimen kemoterapi, rencana pengobatan, informed consent, persiapan obat, } \\
\text { pemberian, monitor kemoterapi dan respon serta efek samping kemoterapi }\end{array}$ & 1 & 20 \\
\hline
\end{tabular}

Tabel 4. Penerapan MSP pada pasien LLA

\begin{tabular}{lccc}
\hline Pertanyaan penelitian & Pra & Pasca & $\mathrm{p}$ \\
\cline { 2 - 3 } & $\mathrm{n}=24$ & $\mathrm{n}=23$ & \\
\hline Apakah menurut responden medication safety practice telah dilakukan & & & $0,019^{*}$ \\
pada pasien kanker anak khususnya kasus LLA? & & \\
Sudah & 17 & 23 \\
Belum & 4 & 0 \\
Tidak tahu & 3 & 0 \\
${ }^{*} \mathrm{p}<0,05$, secara statistik berbeda bermakna terhadap implementasi MSP sesudah intervensi &
\end{tabular}

Pengetahuan responden mengenai apa saja yang termasuk dalam MSP dijabarkan dalam Tabel 3. Tabel 3 menunjukkan tidak semua responden menjawab pertanyaan, terlihat bahwa sesudah intervensi, pemahaman sebagian besar responden mengenai definisi MSP meningkat dari 42\% menjadi $87 \%$.

Tabel 4 menunjukkan pemahaman responden perihal implementasi MSP pada pelayanan kemoterapi anak. Dari tabel tersebut terlihat adanya peningkatan signifikan dalam hal penerapan $M S P$ pascaintervensi dibanding sebelum intervensi $(\mathrm{p}=0,019)$

Tabel 5 menunjukkan beberapa tindakan MSP yang sudah diterapkan pada kemoterapi LLA anak. Terdapat peningkatan penerapan sesudah intervensi dibandingkan sebelum intervensi beberapa tindakan antara lain identifikasi pasien, prinsip 6 benar cara pemberian obat, perencanaan pemberian dan peresepan kemoterapi sesuai protokol, penggunaan formulir pemesanan dan peresepan obat kemoterapi yang standar, dan labelisasi obat kemoterapi yang standar. Penerapan double check pada penyiapan dan pengoplosan obat kemoterapi sudah dilakukan baik sebelum dan sesudah intervensi. Menurut responden, sedikit petugas yang sudah melakukan dokumentasi dalam pemberian kemoterapi dan penyiapan obat di instalasi khusus terpadu. Tindakan aspetik, pendidikan dan informed consent serta monitoring efek samping obat belum dilakukan secara optimal oleh banyak petugas.

\section{Pembahasan}

Upaya preventif dalam tindak keamanan pasien, terutama di bidang onkologi, memberikan dampak yang positif. Usaha tersebut diteliti Womers $\mathrm{dkk}^{3}$ yang melaporkan hasil bahwa dengan diadakannya pendekatan melalui instalasi dengan sistem multidisiplin terhadap keselamatan pasien (medication patient safety) maka tingkat kesalahan pada pemberian obat kemoterapi turun dari 6,2/1000 dosis kemoterapi rawat inap menjadi 1,0/1000 dosis. Keselamatan pasien dianggap sebagai indikator penting dari kualitas asuhan 
Sri Mulatsih dkk: Pemahaman perawat mengenai medication safety practice (MSP) di bangsal perawatan kanker anak

Tabel 5. MSP yang telah diterapkan pada kemoterapi anak dengan LLA dan pengetahuan dasar kemoterapi

\begin{tabular}{llcc}
\hline & Apa sajakah MSP yang telah diterapkan pada kemoterapi anak dengan LLA? & & \\
\hline No & Jawaban responden & Pra & Pasca \\
& & $\mathrm{n}=24(\%)$ & $\mathrm{n}=23(\%)$ \\
\hline a & Tindakan aseptik antiseptik & $4(17)$ & $0(0)$ \\
b & Double check pada penyiapan dan pengoplosan obat kemoterapi & $12(50)$ & $12(52)$ \\
c & Identifikasi pasien & $1(4)$ & $10(43)$ \\
d & Informed cosent keluarga + edukasi & $14(58)$ & $4(17)$ \\
e & Penerapan prinsip 6 benar cara pemberian obat. & $6(25)$ & $20(87)$ \\
f & Perencanaan pemberian dan peresepan kemoterapi sesuai protokol. & $6(25)$ & $16(70)$ \\
g & Monitoring efek samping obat & $12(50)$ & $4(17)$ \\
h & Dokumentasi dalam pemberian kemoterapi & $1(4)$ & $0(0)$ \\
i & Penyiapan obat di instalasi khusus terpadu & $2(8)$ & $1(4)$ \\
j & Penerapan form pemesanan dan peresepan obat kemoterapi yang standar & $0(0)$ & $13(57)$ \\
k & Penerapan labelisasi obat kemoterapi yang standar & $0(0)$ & $5(22)$ \\
17 & Apakah responden pernah mengikuti pelatihan mengenai pemberian kemoterapi yg aman? & & \\
& Sudah & $8(33)$ & $21(91)^{*}$ \\
& Belum & $16(67)$ & $2(9)$ \\
*p=0,001, p<0,05, secara statistik bermakna bahwa 91\% responden sudah mendapatkan pelatihan mengenai kemoterapi pada \\
periode sesudah intervensi.
\end{tabular}

keperawatan dan perawat memegang tanggung jawab untuk mempertahankan keselamatan pasien. ${ }^{4}$

Pada pengamatan pasca intervensi didapatkan pengetahuan responden mengenai MSP meningkat bermakna pada poin responden yang pernah mendengar istilah MSP dan responden yang mendapat materi mengenai MSP. Seluruh responden pasca intervensi $(23$ orang) pernah mendengar istilah MSP, dan 22 dari 23 orang mengetahui definisi MSP. Kesadaran responden dalam praktik pemberian kemoterapi yang aman juga sudah baik, seluruh responden menganggap MSP perlu untuk diketahui oleh tenaga medis yang terlibat dalam pemberian kemoterapi.

Pra tes jawaban responden mengenai apakah MSP itu masih beragam. Namun, pada pengamatan pasca tes, jawaban responden umumnya mengarah ke definisi MSP, yaitu kebijakan dan prosedur aman kemoterapi yang bermula dari review informasi klinis, seleksi regimen kemoterapi, rencana pengobatan, informed consent, persiapan obat, pemberian, monitor kemoterapi dan respons serta efek samping kemoterapi. Terdapat 3 responden yang tidak memberikan/mengisi jawaban mengenai pertanyaan tersebut. Kesalahan peneliti tidak meneliti ulang atas jawaban yang ditulis/ tidak dilakukan klarifikasi.

Studi retrospektif oleh Walsh $\mathrm{dkk}^{5}$ menunjukkan angka kejadian ME pada kanker anak lebih tinggi dibanding dewasa, yaitu $18,8 \%$ vs $7,1 \%$ dengan kejadian ME terbanyak adalah prosedur pemberian obat (56\%). Medication patient safety sebagai prosedur standar yang aman dalam pengobatan kemoterapi sangat dibutuhkan agar sistem berjalan sesuai dengan prosedur, sehingga luaran pasien dengan kemoterapi menjadi lebih baik. Ford dkk ${ }^{6}$ melaporkan kesalahan dalam frekuensi dan jenis obat yang dimasukkan pada bangsal onkologi di rumah sakit besar di Amerika Serikat, walaupun sudah menerapkan panduan keselamatan. Pada pengamatan pra tes, 17 dari 24 responden menyatakan MSP telah dilakukan pada kemoterapi anak dengan LLA. Sementara itu, seluruh responden pasca tes menyatakan MSP telah diterapkan pada kemoterapi anak dengan LLA.

Pada pengamatan pra tes, MSP yang telah diterapkan menurut jawaban terbanyak, antara lain double check pada penyiapan dan pengoplosan obat kemoterapi, edukasi kepada pasien beserta keluarga dan informed consent, monitoring efek samping obat. Sementara pada pengamatan posca tes, menurut jawaban terbanyak, antara lain double check pada penyiapan dan pengoplosan obat kemoterapi, identifikasi pasien, penerapan prinsip 6 benar cara pemberian obat, perencanaan pemberian dan peresepan kemoterapi sesuai protokol, penerapan formulir pemesanan, dan peresepan obat kemoterapi 
yang standar. Jumlah responden yang telah mengikuti pelatihan mengenai pemberian kemoterapi yang aman meningkat bermakna. Pada pra tes, hanya 8 dari 24 responden yang pernah mengikuti pelatihan. Sementara pasca tes, responden yang mengikuti pelatihan 21 dari 23 responden.

Kriteria prosedur pemberian kemoterapi standar yang dapat dipakai untuk acuan medication patient safety, antara lain 1) dapat digunakan di poliklinik dan bangsal perawatan kanker, 2) mudah dipahami dan praktis digunakan secara klinis, 3) realistik dan dapat diterapkan, 4) valid dan berdasarkan bukti ilmiah atau konsensus yang kuat, 5) reliable sehingga dapat diimplementasikan secara konsisten, dapat diakses serta di follow up secara kontinyu, 6) dapat diukur sehingga dapt dilakukan audit internal dan eksternal, dan 7) merupakan petunjuk praktis yang siap dilaksanakan seperti SPO. ${ }^{7}$ Salah satu cara mencegah kejadian medication error dengan selalu dilakukan edukasi kepada tenaga kesehatan, termasuk perawat mengenai obat baru, obat-obat non-furmulary, obat-obat highalert, dan cara pencegahan medication error. ${ }^{8}$

Pendidikan yang berkelanjutan akan memperbaiki perawatan kesehatan dan meningkatkan efektifitas sehingga patient safety bisa selalu ditingkatkan. ${ }^{9}$ Beberapa penyebab kesalahan pemberian obat oleh perawat, antara lain 1) interupsi atau gangguan pekerjaan lain, misalnya karena menerima telpon, panggilan pasien, 2) ketrampilan kalkulasi obat yang kurang, dan 3) pendidikan dan kepatuhan terhadap protap yang tidak baik. ${ }^{10}$ Pendidikan berkelanjutan dapat meningkatkan kualitas pelayanan kesehatan keperawatan dan meningkatkan efektivitas perawatan pasien sehingga patient safety dapat selalu dijaga dan ditingkatkan.

\section{Kesimpulan}

Pemahaman perawat mengenai MSP cukup baik dan semakin baik setelah dilakukan pelatihan, hanya petugas belum memahami secara optimal terkait dengan MSP serta sumber-sumber penyebab terjadinya
MSP. Diperlukan pelatihan yang lebih spesifik untuk mendapatkanluara pelatihan yang baik sehingga pengetahuan dan ketrampilan perawat menjadi lebih baik. Dengan demikian mutu pelayanan dan patient safety akan selalu bisa dijaga dan ditingkatkan.

\section{Daftar pustaka}

1. Supriyadi E, Widjajanto PH, Purwanto I, Cloos J, Veerman AJ, Sutaryo S. Incidence of childhood leukemia in Yogyakarta, Indonesia, 1998-2009. Pediatr Blood Cancer 2011;57:588-93.

2. CNO. Practice standard medication, revised 2008. College of Nurses of Ontario. Ontario: CNO; 2008.

3. Womer RB, Tracy E, Soo-Hoo W, Bickert B, DiTaranto $\mathrm{S}$, Barnsteiner JH. Multidisciplinary systems approach to chemotherapy safety: rebuilding processes and holding the gains. J Clin Oncol 2002;20:4705-12.

4. Tu YC, Wang RH. High-quality nursing health care environment: the patient safety perspective. $\mathrm{Hu} \mathrm{Li} \mathrm{Za}$ Zhi Jun 2011;58:93-8.

5. Walsh KE, Dodd KS, Seetharaman K, Roblin DW, Herrinton LJ, Gurwitz JH dkk. Medication errors among adults and children with cancer in the outpatient setting. J Clin Oncol 2008;27:891-6.

6. Ford CD, Killebrew J, Fuggit P, Jacobsen J, Prystas EM. Study of medication errors on a community hospital oncology ward. J Oncol Pract 2006;2:149-54.

7. Jacobson JO, Polovich M, McNiff KK, LeFebvre $\mathrm{KB}$, Cummings $\mathrm{C}$, McCorkle MR, dkk American society of clinical oncology/oncology nursing society chemotherapy administration safety standards. Oncology Nursing Forum 2009;36:651-8.

8. American Hospital Association (AHA). Health research \& educational trust, and the institute for safe medication practices. Pathway for Medication Safety 2002;2:33

9. Fumic N., Marinovic M., Brajan D. Continous nursing education to improve the quality of health care. Acta Med Croatica 2014;68 Suppl 1:13-6.

10. Ofusu R, Jarrett P. Reducing nurse medicine administration errors. Nursing Times 2015;111:12-14. 